\title{
Estimating a marginal abatement cost curve for greenhouse gas emissions from Irish agriculture using farm-level data
}

J P Breen ${ }^{1,2}$, T Donnellan $^{1}$, M Wallace ${ }^{3}$

${ }^{1}$ Rural Economy Research Centre, Teagasc, Athenry, Co. Galway, Ireland, ${ }^{2}$ Department of Agricultural Economics, University of Missouri-Columbia, Columbia, Missouri, United States, ${ }^{3}$ School of Agriculture, Food Science and Veterinary Medicine, University College Dublin, Belfield, Dublin 4, Ireland

Email: james.breen@teagasc.ie

Introduction In 2008, the EU made a commitment to achieve at least a $20 \%$ reduction in greenhouse gas (GHG) emissions by 2020 compared to 1990 levels (European Commission 2008). In order to achieve this target, each member state (MS) has been set an emissions reduction target for their non-Emissions Trading Sector (ETS). These emissions reduction targets vary by MS, Ireland, Denmark and Luxembourg are faced with a reduction of 20 percent in their non-ETS emissions by 2020 , the largest of any MS. Agriculture currently accounts for approximately $40 \%$ of Ireland's non-ETS emissions and so the $20 \%$ reduction target may have ramifications for Irish agriculture. In order to fully understand the implications of an emissions reduction target for Irish agriculture, it is necessary to first quantify the marginal cost of emissions abatement in Irish agriculture. This paper uses data from the Irish National Farm Survey (NFS) to estimate a marginal abatement cost curve (MACC) for GHG emissions from Irish agriculture.

Materials and methods An individual farm-level linear programming (LP) model has been constructed using 2006 NFS data (Connolly et al. 2007) and replicated for all of the 1,160 farms in the 2006 NFS dataset. The model consists of a number of traditional farm activities, as well as two forestry activities, two biomass crop activities and a number of alternative abatement technology activities. The returns to each activity are calculated based on each individual farm's price and cost information from the 2006 NFS. The price of outputs sold and inputs purchased are inflated using output and input price projections from the FAPRI-Ireland aggregate level model (Binfield et al. 2008). The total GHG emissions for each farm within the model are calculated using activity data from the model and Tier 1 and Tier 2 GHG emissions factors, the approach taken is designed to be consistent with the approach used in the Irish National Inventory Report (EPA 2008). By applying farm-weights from the NFS, each individual farm within the farm-level model is weighted up to the sectoral level. The objective function of this LP model is to maximize the overall discounted gross margin for the agricultural sector. The MACC is estimated by introducing an emissions tax into the model, which is then increased incrementally. This allows for the calculation of the volume of emissions abated at each increment of the emissions tax.

Results Figure 1 compares the MACC for two specialist dairy farms, Dairy $>80 \%$ is a dairy farm where more than $80 \%$ of the livestock units (LU) are dairy cows, while Dairy $<40 \%$ is a dairy farm where less than $40 \%$ of the LU are dairy cows. The slope of the Dairy $>80 \%$ curve is initially steeper due to the higher proportion of dairy cows in the herd which have a higher marginal cost of emissions abatement. Figure 2 below presents the aggregated MACC for Irish agriculture. The curve is initially relatively flat, largely due to the abatement of emissions from the drystock sector where the marginal cost of abating emissions is lower due to the relatively low gross margin earned by these emissions. The slope of the curve steepens due to a greater proportion of emissions from dairy and cereal production being abated. These activities have a higher gross margin and therefore a higher marginal cost of abatement.

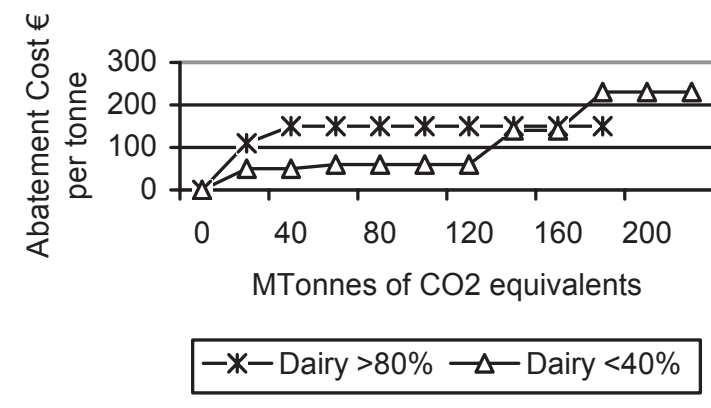

Figure 1 MACC for Example Dairy Farms

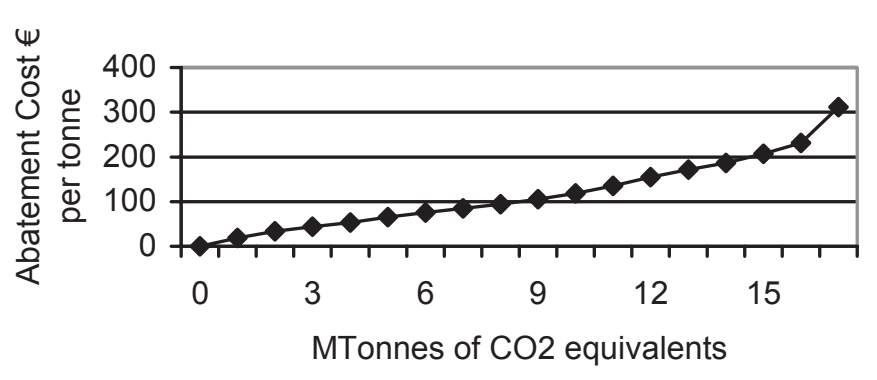

Figure 2 MACC for Irish Agriculture

Conclusions The results presented in Figure 1 illustrate the variability that can exist in the marginal cost of emissions abatement both within farms and between farms due to issues related to farm type, production system etc. This variability in the marginal cost of emissions abatement is vital to understanding how alternative emissions reduction targets will impact on Irish agriculture.

Acknowledgements The authors acknowledge funding from the Department of Agriculture, Fisheries and Food

\section{References}

Binfield, J., Donnellan, T., Hanrahan, K. and Westhoff, P. Baseline Outlook for EU and Irish Agriculture, Teagasc

Connolly L, Kinsella A, Quinlan G and Moran B 2007 National Farm Survey 2006. Teagasc Rural Economy Research Centre

Environmental Protection Agency 2008. Ireland National Inventory Report 2008. Wexford, Ireland.

European Commission 2008 Commission Staff Working Document Package of Implementation measures for the EU's objectives on climate change and renewable energy for 2020 Brussels, 23.01.2008 SEC 2008 85/3 http://ec.europa.eu/energy/climate_actions/doc/2008_res_ia_en.pdf 